\title{
THz and IR Spectroscopy of Molecular Systems That Simulate Function-Related Structural Changes of Proteins
}

\author{
N. N. Brandt, ${ }^{1}$ A. Yu. Chikishev, ${ }^{1}$ A. A. Mankova, ${ }^{1}$ M. M. Nazarov, ${ }^{1}$ I. K. Sakodynskaya,${ }^{2}$ \\ and A. P. Shkurinov ${ }^{1}$ \\ ${ }^{1}$ Faculty of Physics and International Laser Center, Moscow State University, Moscow 119991, Russia \\ ${ }^{2}$ Faculty of Chemistry, Moscow State University, Moscow 119991, Russia \\ Correspondence should be addressed to A. A. Mankova, mankova@physics.msu.ru
}

Copyright (C) 2012 N. N. Brandt et al. This is an open access article distributed under the Creative Commons Attribution License, which permits unrestricted use, distribution, and reproduction in any medium, provided the original work is properly cited.

\begin{abstract}
The activity of enzymes in organic solvents substantially increases in the presence of crown ethers. Tris(hydroxymethyl)aminomethane (tris) is chosen as a model compound to simulate the interaction of surface amino groups of proteins with crown ether. The methods of FTIR and time-domain THz spectroscopy are used to study the interaction of tris with 18-crown-6. The THz spectra of the complexes are measured for the first time.
\end{abstract}

Keywords: THz spectroscopy, FTIR spectroscopy, tris, crown

\section{Introduction}

The analysis of the protein structure is an important problem in the study of biological molecules, since the functional activity of protein is related to structural changes. It is known that the enzymatic activity in organic solvents (e.g., of chymotrypsin) sharply increases in the presence of crown ethers [1,2]. One of the possible reasons is the interaction of crown-ether molecules with the surface amino groups of protein. Note that the vibrational bands of the amino groups are strongly overlapped with the protein amide bands, and the methods of IR and Raman spectroscopy cannot be directly employed in the corresponding study. However, the spectroscopic methods can be used to investigate the interaction of amino groups with crown ethers in model chemical systems. One of the model compounds is tris(hydroxymethyl)aminomethane (tris) $\left(\mathrm{HOCH}_{2}\right)_{3} \mathrm{C}-\mathrm{NH}_{2}$ [3], and 18-crown-6 $\left(\mathrm{C}_{12} \mathrm{H}_{24} \mathrm{O}_{6}\right)$ is the crown ether in our experiments. The purpose of this work is the detection of the spectral changes in the IR and $\mathrm{THz}$ spectra due to the interaction of amino group with crown ether.

\section{Experimental}

We employ tris and 18-crown-6 from REAHIM. Tris and its complexes with 18-crown-6 at several relative concentrations are prepared as powders using the 20-hour-long lyophilization of solutions with 
different $\mathrm{pH}$. Hydrochloric acid is used for the adjustment of $\mathrm{pH}(\mathrm{pH} 10, \mathrm{pH} 8.3, \mathrm{pH} 7.8, \mathrm{pH} 3)$. The samples represent pressed tablets with a diameter of $5 \mathrm{~mm}$ and a thickness of about $300 \mu \mathrm{m}$. For the measurement of the IR spectra, we employ a Nicolet 6700 FTIR spectrometer interfaced with a Smart Orbit ATR unit. The THz setup is described in [4].

\section{Results and Discussion}

In the wavenumber interval $1500-1700 \mathrm{~cm}^{-1}$, the IR spectrum of tris at $\mathrm{pH} 10$ exhibits a single band peaked at about $1586 \mathrm{~cm}^{-1}$, whereas the spectrum of tris at $\mathrm{pH} 3$ exhibits two bands peaked at 1550 and $1628 \mathrm{~cm}^{-1}$. The three bands are detected in the spectra of tris at intermediate $\mathrm{pH}(\mathrm{pH} 7.8$ and $\mathrm{pH} 8.3)$.

The IR spectrum of the complex of tris with 18-crown-6 at a relative molar concentration of $1: 1$ and $\mathrm{pH} 10$ can be well fitted using the spectra of components and polynomial background [5]. The measured spectrum of the complex and the fitting curve are very close to each other except for minor spectral differences in the interval $1050-1200 \mathrm{~cm}^{-1}$. However, the spectrum of the same complex at $\mathrm{pH} 3$ significantly differs from the sum of the spectra of components in the fingerprint range. Note that the two bands of the protonated tris $(\mathrm{pH} 3)$ peaked at 1550 and $1628 \mathrm{~cm}^{-1}$ are changed by a single band peaked at $1587 \mathrm{~cm}^{-1}$ with a shoulder at $1600 \mathrm{~cm}^{-1}$. These results indicate that the protonated tris is involved in significantly stronger interaction with 18-crown-6.

Figure 1(a) demonstrates the $\mathrm{THz}$ spectra of tris at several $\mathrm{pH}$. It is seen that the spectrum of the protonated tris $(\mathrm{pH} 3)$ substantially differs from the remaining spectra, since it does not exhibit developed bands peaked at 1.51, 1.73, 2.11, and 2.30 THz. Figure 1(b) shows the spectra of tris at pH10, 18-crown6 , and the complexes at relative molar concentrations (tris/crown) of $1: 1$ and $1: 10$ and $\mathrm{pH} 10$. Note that the spectra of the complexes at relative molar concentrations of $1: 2$ and $1: 5$ (not shown) slightly differ from the spectrum of the complex at $1: 10$. The complex formation leads to significantly lower intensities of the bands peaked at 1.52,1.75, and $2.30 \mathrm{THz}$. When the relative molar concentration of 18-crown- 6 increases to 10, the above bands of the pure tris almost vanish and the broad band at $1.65 \mathrm{THz}$ can be assigned to the free 18-crown-6. Nevertheless, the band peaked at $2.11 \mathrm{THz}$ survives in the spectra of complexes.

Figure 1(c) demonstrates the spectra of tris at $\mathrm{pH} 3,18$-crown-6, and the complexes at relative molar concentrations of $1: 1$ and $1: 10$. As distinct from the results at $\mathrm{pH} 10$, the spectra of the complexes at intermediate relative concentrations of $1: 2$ and $1: 5$ (not shown) differ from the spectra at $1: 1$ and $1: 10$. Note also significant spectral changes due to the interaction with the crown ether. The strongest spectral changes correspond to the transition from the spectrum of the protonated tris to the spectrum of the equimolar complex. The latter exhibits three developed bands. The first (broadest) band with a width of about $0.4 \mathrm{THz}$ is peaked at about $1.30 \mathrm{THz}$. Two remaining (narrower) bands are peaked at 2.10 and $2.31 \mathrm{THz}$. The results indicate structural changes of the protonated tris caused by the interaction with 18-crown-6. It is seen that an increase in the relative concentration of the crown ether leads to a decrease in the intensity of the band peaked at $1.30 \mathrm{THz}$. Apparently, the band is not assigned to 18-crown- 6 . We assume that the spectra of complexes with high relative concentrations of the crown ether can be represented as the sums of the spectra of the crown ether and the tris complex with the crown ether at a relative concentration of $1: 1$. Based on such an assumption, we assume that the broad band can be assigned to the protonated tris that is structurally modified owing to the interaction with the crown ether. Thus, the spectral data indicate two transformations of the protonated tris related to (i) the transition 


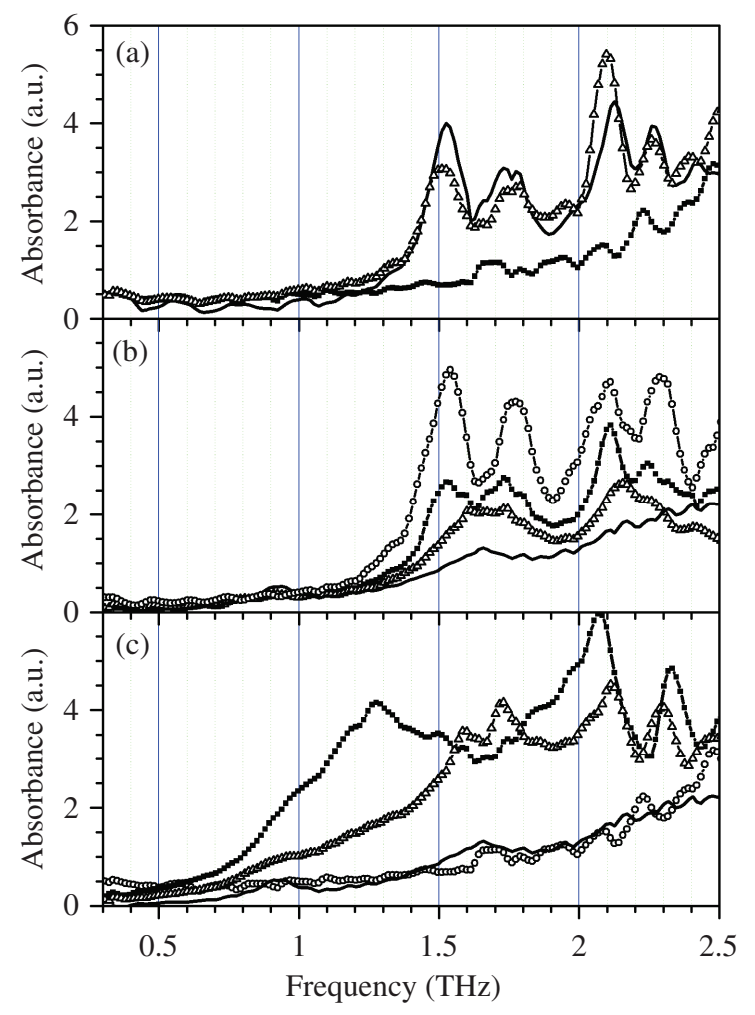

Figure 1: THz spectra of (a) tris at (solid line) pH10, (triangles) pH7.8, and (squares) pH3; (b) tris-18crown- 6 complexes at $\mathrm{pH} 10$ and relative molar concentrations of (circles) $1: 0$, (squares) $1: 1$, (triangles) $1: 10$, and (solid line) $0: 1$; (c) tris-18-crown-6 complexes at $\mathrm{pH} 3$ and relative molar concentrations of (circles) $1: 0$, (squares) $1: 1$, (triangles) $1: 10$, and (solid line) $0: 1$.

from the unbound molecule to the equimolar complex and (ii) an increase in the relative concentration of the crown ether.

Note that the spectra of the complexes of protonated tris at relative concentrations of $1: 5$ and $1: 10$ are similar to the spectrum of the equimolar complex of tris at $\mathrm{pH} 10$. This circumstance can be an indication of the deprotonation of the protonated tris in the complexes with high relative concentrations of the crown ether.

\section{References}

[1] J. Broos, I. K. Sakodinskaya, J. F. J. Engberson, W. Verboom, and D. N. Reinhoudt, "Large activation of serine proteases by pretreatment with crown ethers," Journal of the Chemical Society, Chemical Communications, vol. 1995, no. 2, pp. 255-256, 1995.

[2] D. J. Van Unen, J. F. J. Engberson, and D. N. Reinhoudt, "Large acceleration of $\alpha$ chymotrypsin-catalyzed dipeptide formation by 18-crown-6 in organic solvents," Biotechnology and Bioengineering, vol. 59, no. 5, pp. 553-556, 1998. 
[3] K. Griebenow and A. M. Klibanov, "Can conformational-changes be responsible for solvent and excipient effects on the catalytic behavior of subtilisin carlsberg in organic-solvents?" Biotechnology and Bioengineering, vol. 53, no. 4, pp. 351-362, 1997.

[4] M. M. Nazarov, A. P. Shkurinov, and V. V. Tuchin, "Tooth study by terahertz time-domain spectroscopy," in Saratov Fall Meeting, Optical Technologies in Biophysics and Medicine IX, vol. 6791 of Proceedings of SPIE, September 2007.

[5] N. N. Brandt, O. O. Brovko, A. Y. Chikishev, and O. D. Paraschuk, "Optimization of the rollingcircle filter for Raman background subtraction," Applied Spectroscopy, vol. 60, no. 3, pp. 288-293, 2006. 


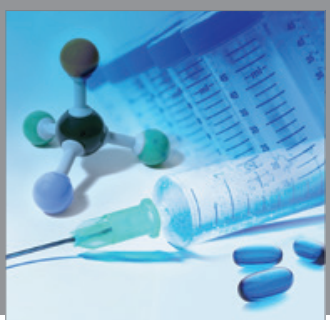

International Journal of

Medicinal Chemistry

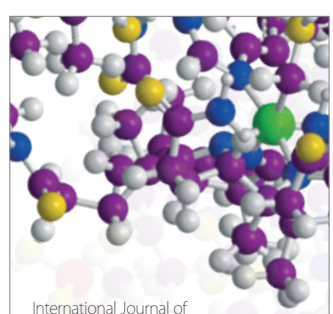

Carbohydrate Chemistry

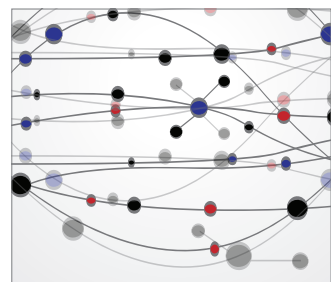

The Scientific World Journal
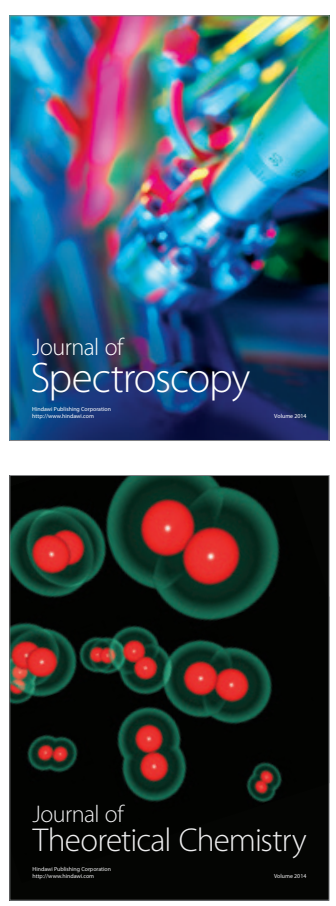
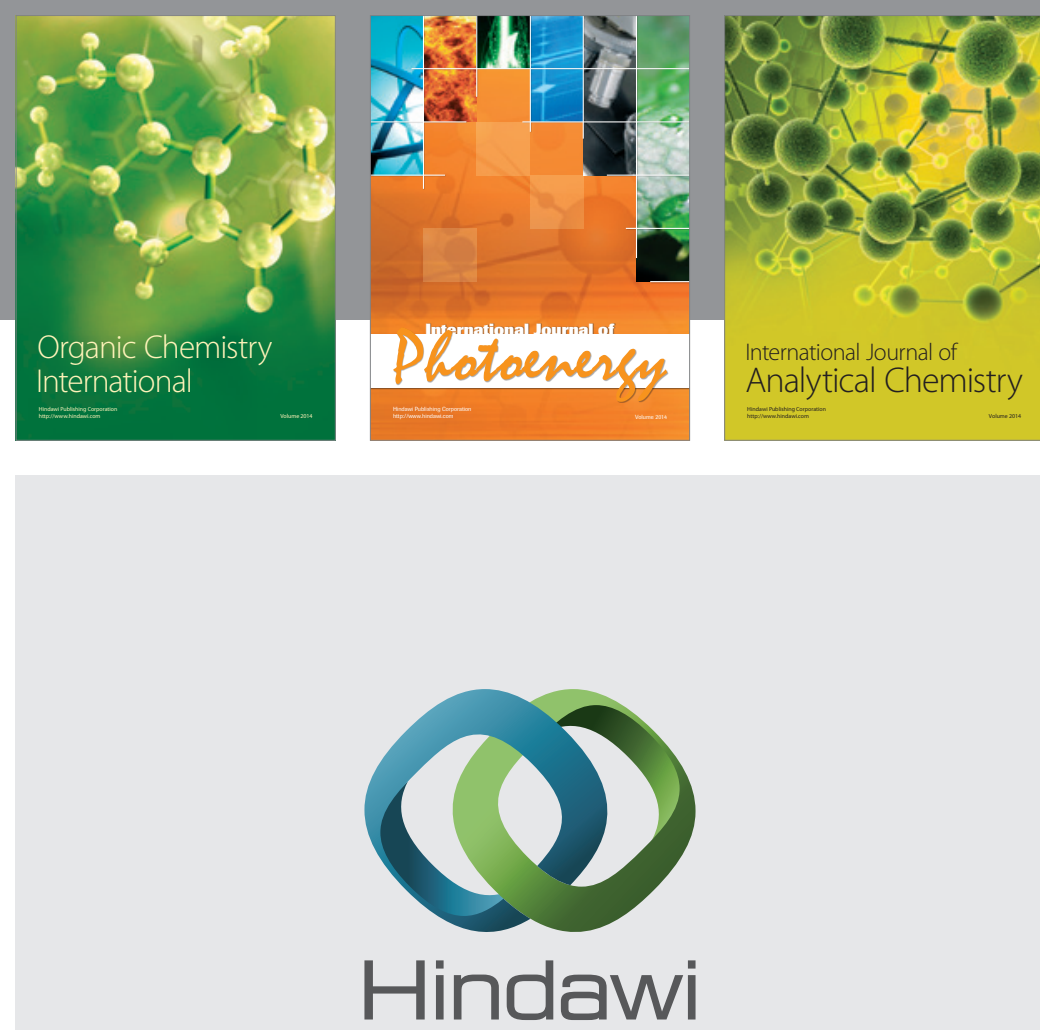

Submit your manuscripts at

http://www.hindawi.com
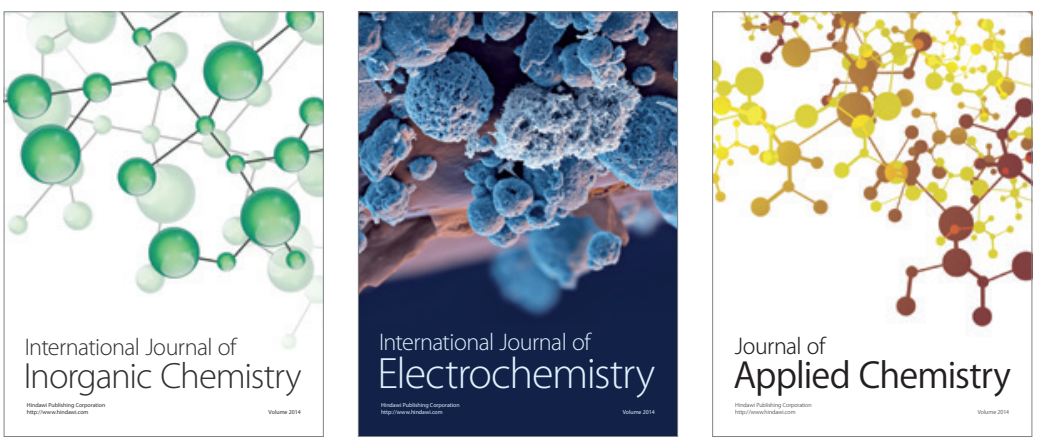

Journal of

Applied Chemistry
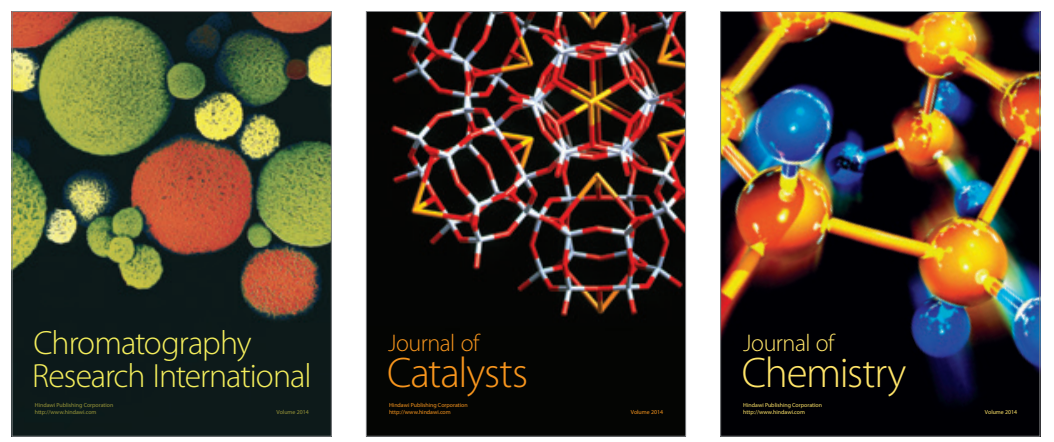
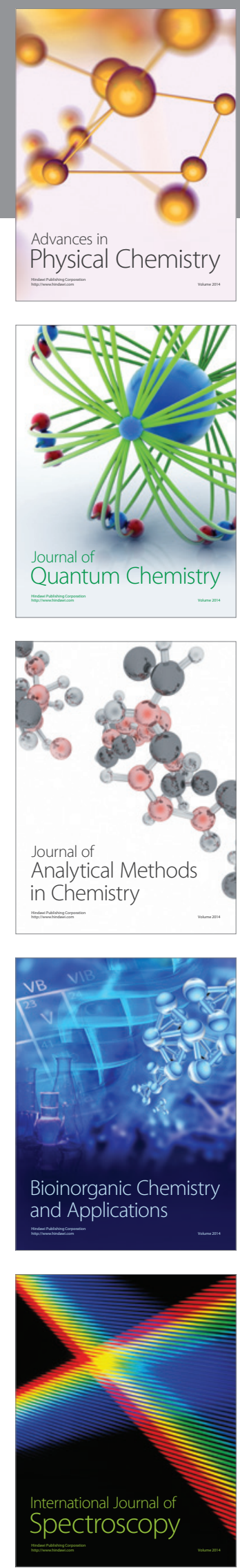